УДК 681.51

DOI https://doi.org/10.32838/2663-5941/2019.3-2/28

\title{
Лисенко О.I.
}

Національний технічний університет України

«Київський політехнічний інститут імені Ігоря Сікорського»

Тачиніна О.М.

Національний авіаційний університет

Кисельов В.Б.

Таврійський національний університет імені В.І. Вернадського

Гуйда О.Г.

Таврійський національний університет імені В.I. Вернадського

\section{АЛГОРИТМ КВАЗІІНВАРІАНТНОГО УПРАВЛІННЯ ЕЛЕКТРОПРИВОДОМ ВЕРТИКАЛЬНОГО ТРАНСПОРТНОГО ЗАСОБУ В РЕЖИМІ СЕРЕДНЬОШВИДКІСНОГО ПІДЙОМУ}

Пропонується алгоритм квазіінваріантного управління (АКУ), який дозволяє зменшити величину поштовхового впливу на швидкість пересування вертикального транспортного засобу. АКУ не потребує використання спеціальних керованих роликів, вимірювача величини поштовху та системи управління роликами.

Ключові слова: иифрове управління, комп 'ютерне моделювання, алгоритм управління, інваріантні системи, адаптивні системи, динамічні системи, конструювання регуляторів, спостерігачі стану.

Вступ. Вертикальні транспортні засоби (ВТЗ) ліфти, активно застосовуються як в житлових будинках, так і на промислових об'єктах [1]. Першою проблемою під час середньо швидкісного підйому ВТЗ $є$ поштовхові навантаження на його привід [2; 5-7]. Ці навантаження сприяють підвищеному зношуванню ВТЗ та створюють умови виникнення дискомфорту в процесі використання ВТЗ для перевезення людей $[2 ; 7]$.

Постановка проблема. Сьогодні основним способом боротьби із поштовховим навантаженням $€$ технологія типу ActiveRollerGuideSystem [7]. У цій технології задіяні спеціальні ролики, що управляються спеціальною системою вимірювання та гасіння поштовхових збурень. У цій статті пропонується алгоритм квазіінваріантного управління (АКУ), який дозволяє зменшити величину поштовхового впливу на швидкість пересування ВТЗ. АКУ не потребує використання спеціальних керованих роликів, вимірювача величини поштовху та системи управління роликами.

Алгоритм квазіінваріантного управління складається із трьох алгоритмів:

1. Алгоритму цифрового пропорційно-інтегрально-диференціального регулятора (ЦПІДрегулятора), який дозволяє забезпечити безпомилкове стеження за постійним задаючим сигналом та прийнятну добротність управління під час стеження за задаючим сигналом, що лінійно змінюється в часі;

2. Алгоритму цифрового регулятора для корекції динамічних характеристик привода;

3. Алгоритму цифрового спостерігача Льюінбергера разом із цифровим вимірювачем току у ланцюзі якоря електропривода, який дозволяє алгоритмічно оцінювати швидкість пересування BT3.

Квазіінваріантність системи управління приводом ВТЗ забезпечується завдяки сумісному використанню властивостей усіх трьох алгоритмів: згладжуючої властивості ЦПІД-регулятора, регулятор корекції динамічних характеристик приводу, властивості цифрового спостерігача Льюінбергера квазіотимально прогнозувати на крок вектор стану приводу.

Розглянемо модельний приклад побудови АКУ.

1. Припустимо, що відома неперервна LTI-модель приводу ВТ3 [3; 4]. Побудуємо комп'ютерну (MATLAB+Simulink) неперервну LTI-модель приводу ВТЗ з урахуванням того, що матриці $\mathrm{A}_{\mathrm{n}}, \mathrm{B}_{\mathrm{n}}, \mathrm{C}_{\mathrm{n}}, \mathrm{D}_{\mathrm{n}}$ мають вигляд:

$$
A_{n}=\left[\begin{array}{cc}
-25 & -7,5 \\
7,5 & 0
\end{array}\right], B_{n}=\left[\begin{array}{cc}
5 & 0 \\
0 & -5
\end{array}\right], C_{n}=\left[\begin{array}{ll}
1 & 0 \\
0 & 1
\end{array}\right], D_{n}=\left[\begin{array}{ll}
0 & 0 \\
0 & 0
\end{array}\right] .
$$




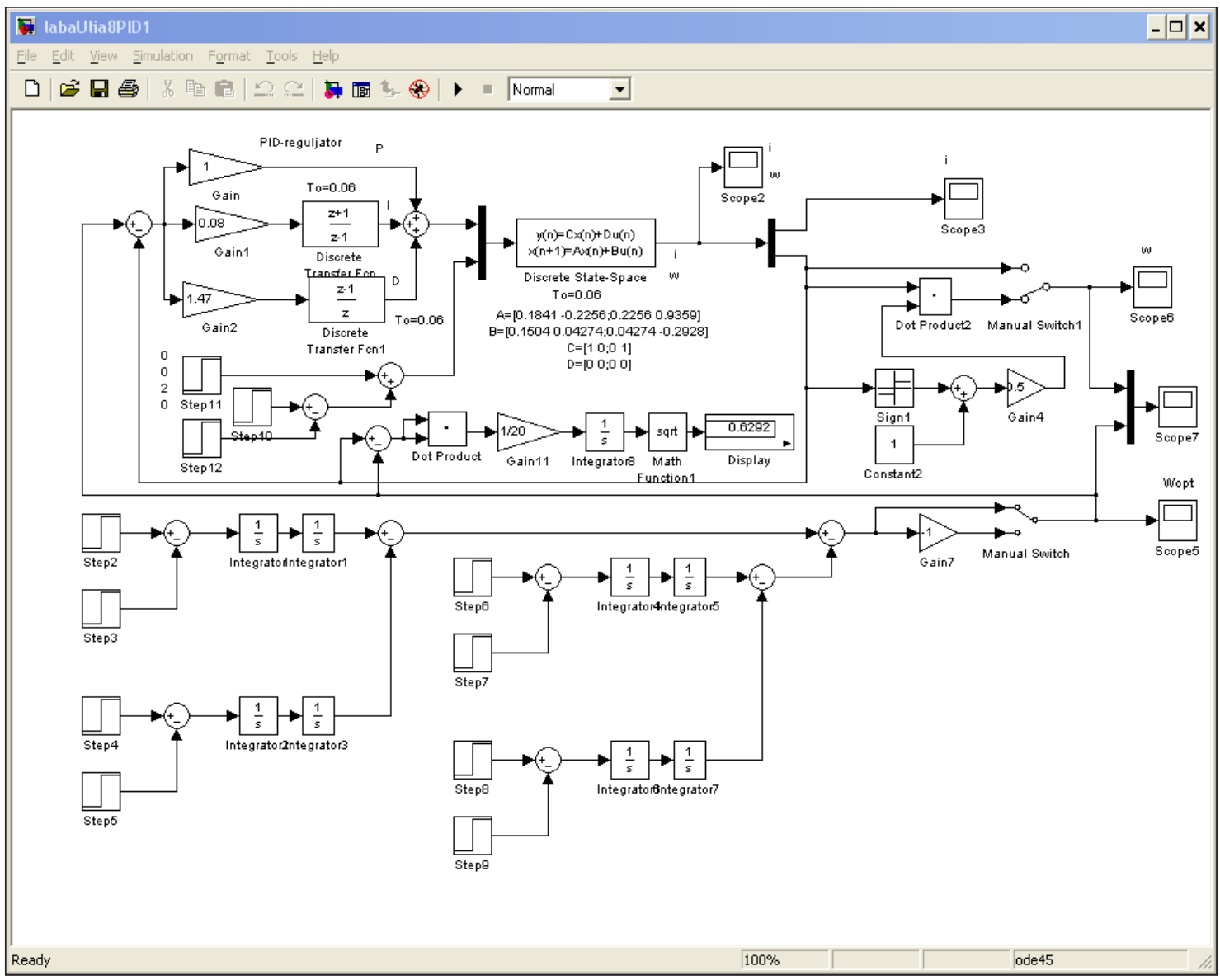

Рис. 1. Структурна схема комп’ютерної дискретної LTI-моделі приводу ВТЗ із ЦПІД-регулятором

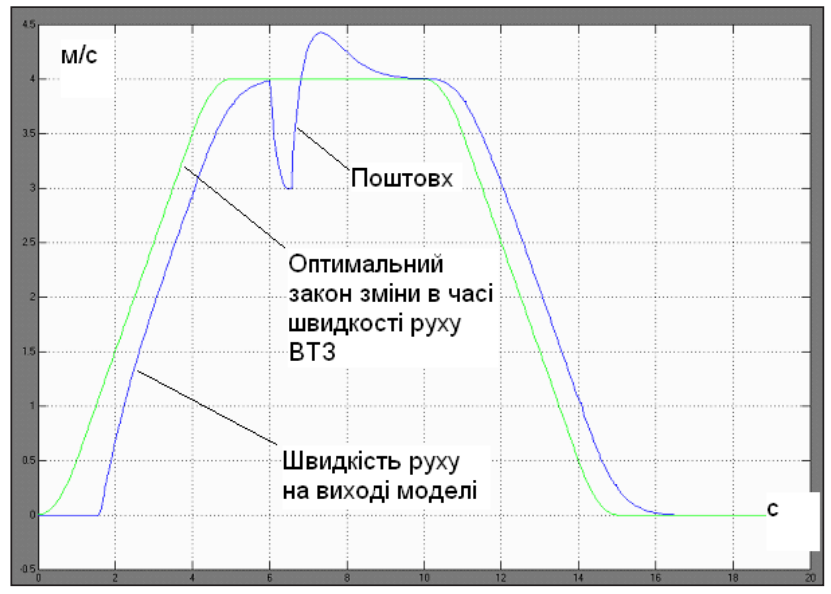

Рис. 2. Графічна ілюстрація впливу поштовхового збурення на швидкість руху ВТЗ вгору, якщо ця швидкість регулюсться ЦПІД-регулятором

2. За допомогою функції c2d(.) будуємо комп'ютерну дискретну LTI-модель приводу ВT3:

$$
A_{d}=\left[\begin{array}{ll}
0.1841 & -0.2256 \\
0.2256 & 0.9359
\end{array}\right], B_{d}=\left[\begin{array}{ll}
0.1504 & 0.04274 \\
0.04274 & -0.2928
\end{array}\right], C_{d}=\left[\begin{array}{ll}
1 & 0 \\
0 & 1
\end{array}\right], D_{d}=\left[\begin{array}{ll}
0 & 0 \\
0 & 0
\end{array}\right],
$$

за умови, що період дискретизації за часом $\mathrm{T}_{0}=0.06 \mathrm{c}$.
3. Використовуючи методику Зіглера-Николса, налаштовуємо ЦПІД-регулятор (див. рис. 1, 2).

4. Виконаємо корекцію динамічних властивостей приводу шляхом синтезу матриці коефіцієнтів корегуючого зворотного зв'язку методом бажаного характеристичного рівняння:

$$
\begin{aligned}
& \mathrm{B} 1=[0.1504 ; 0.04274] \text {; } \\
& \mathrm{K} 05 \mathrm{~b}=\operatorname{acker}(\mathrm{A}, \mathrm{B} 1,[0.50 .5]) \text {; } \\
& \mathrm{K} 05 \mathrm{~b}=\left[\begin{array}{ll}
0.1915 & 2.1337
\end{array}\right] \text {. }
\end{aligned}
$$

Переналаштуємо за методикою ЗіглераНіколса параметри ЦПІД-регулятора для привода iз зкорегованими динамічними характеристиками і виконаємо моделювання (див. рис. 3,4 )

5. Виконуємо розрахунок матричного коефіцієнту підсилення спостерігача Льюінбергера:

$\mathrm{C}=\left[\begin{array}{ll}1 & 0\end{array}\right]$, означає - вимірюється струм якоря. Тоді $\mathrm{HT}=$ acker $\quad\left(\mathrm{A}^{\prime}, \mathrm{C}^{\prime},[0.50 .5]\right) ; \quad \mathrm{HT}=[0.1200$ $-0.6166] ; \mathrm{H}^{0}=\mathrm{HT}^{\prime} ; \mathbf{H 0 5}=[\mathbf{0 . 1 2 0 0} ; \mathbf{- 0 . 6 1 6 6}]$.

Результати моделювання представлені на рис. 5 та 6.

Висновок. Цифровий алгоритм квазіінваріантного управління швидкістю вертикального транспортного засобу сконструйовано із вико- 


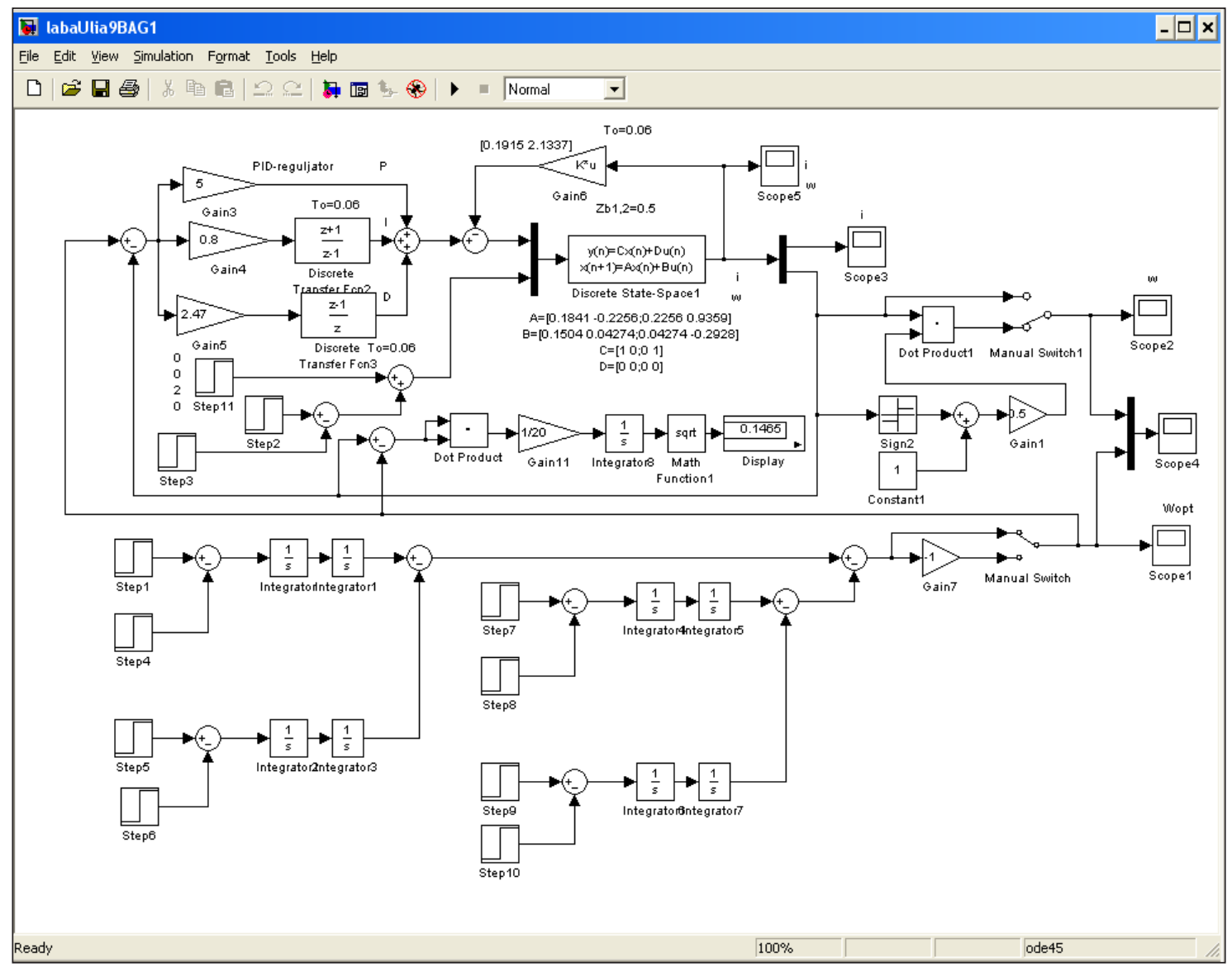

Рис. 3. Структурна схема комп'ютерної дискретної LTI-моделі приводу BT3 із ЦПІД-регулятором та алгоритмом корекції його динамічних характеристик

ристанням трьох цифрових алгоритмів: пропорційно-диференціального регулятора; регулятора, що корегує динамічні властивості приводу; аналітичного вимірювача швидкості переміщення ВТЗ.

Сумісне використання цих трьох алгоритмів дозволяє в 3-4 рази зменшити середньоквадратичну помилку стеження за оптимальним законом руху ВТ3, яка викликана поштовховою збурюючою дією. Тобто стає обгрунтованим і можливим для практичної реалізації застосування лише алгоритмічного способу покращення динамічних властивостей ВТЗ, який не потребує використання додаткового обладнання.

Подальшим напрямом досліджень слід вважати конструювання квазіадаптивного алгоритму управління приводом ВТЗ для великих швидкостей підйому, який, окрім поштовхового впливу, зменшує ще й і вібраційне навантаження на ВТЗ.

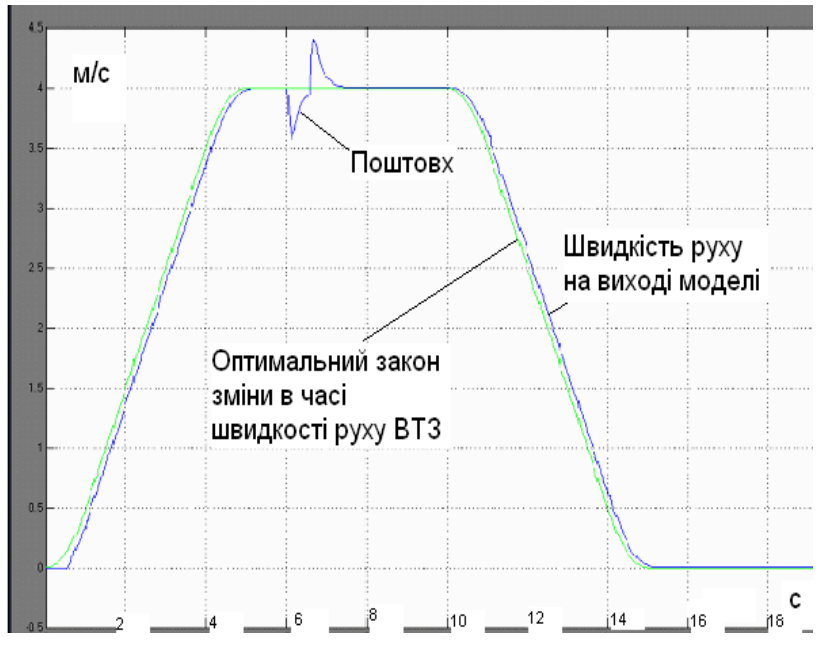

Рис. 4. Графічна ілюстрація впливу поштовхового збурення на швидкість руху ВТЗ вгору, якщо ця швидкість регулюється ЦПЦД-регулятором, який налаштовано на привід із алгоритмом корекції його динамічних характеристик 


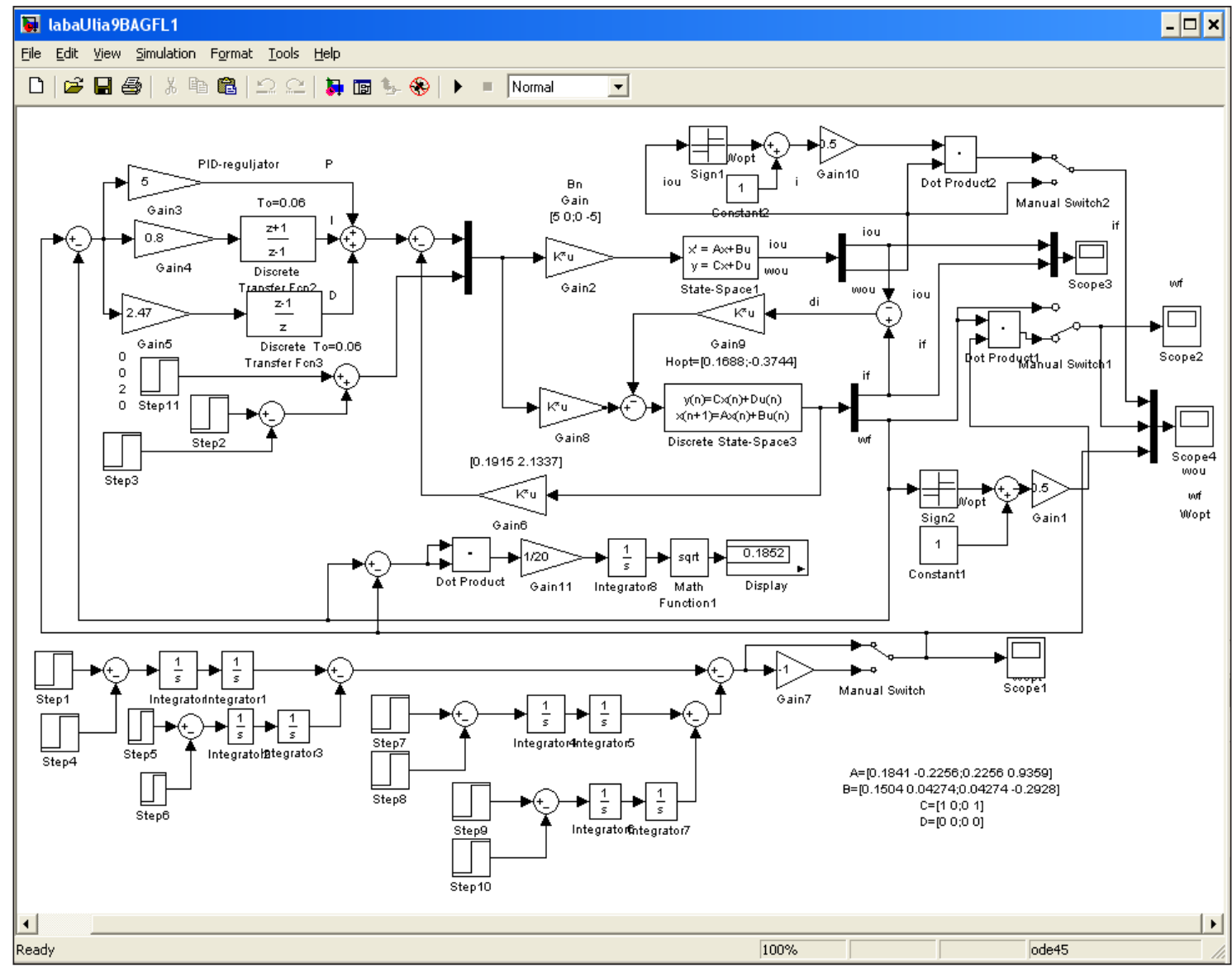

Рис. 5. Структурна схема комп'ютерної дискретної LTI-моделі приводу BT3 із алгоритмом квазіінваріантного управління цим приводом (ЦПІД-регулятор, алгоритмом корекції динамічних характеристик приводу, спостерігач Льюінбергера)

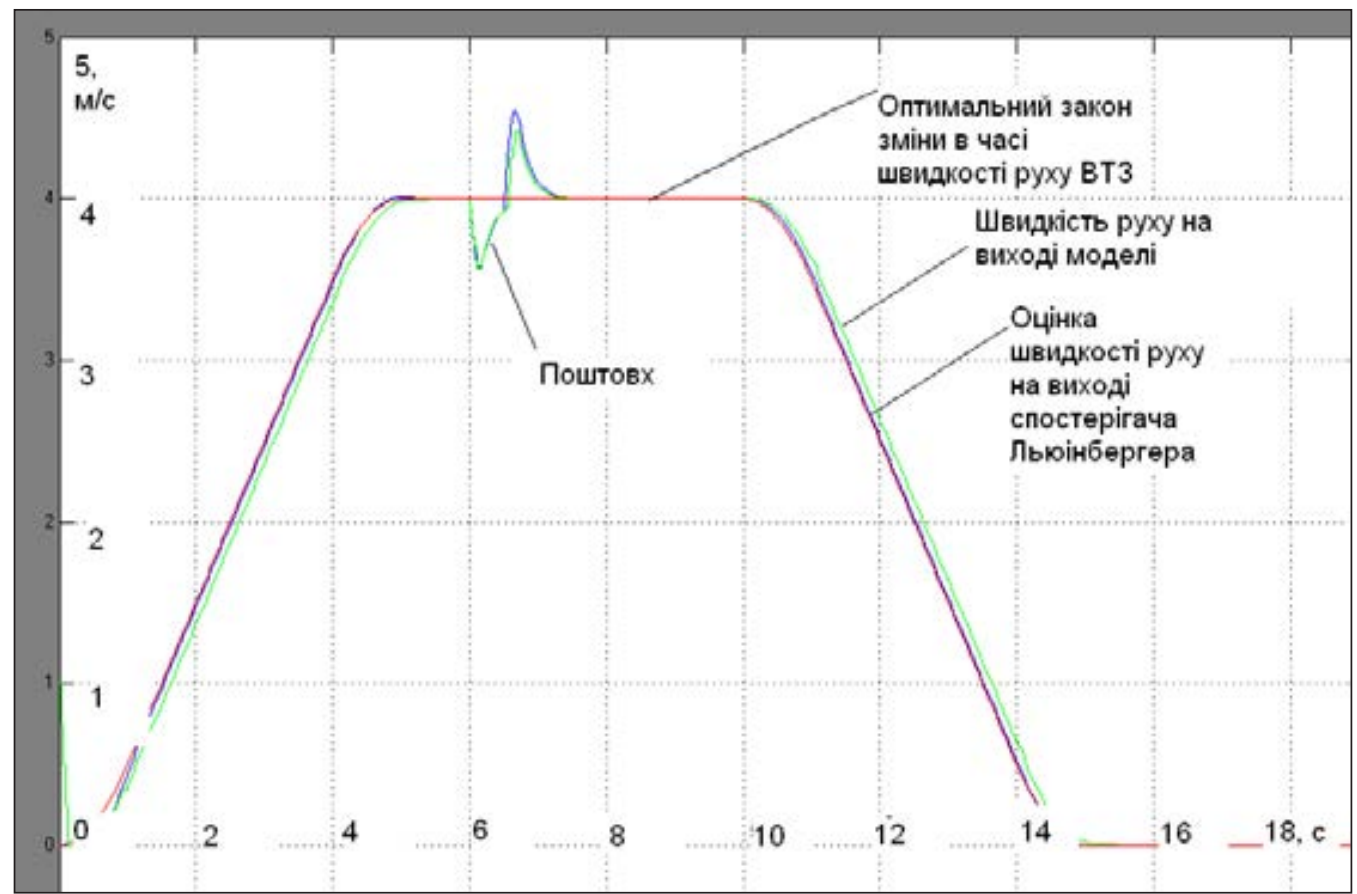

Рис. 6. Графічна ілюстрація впливу поштовхового збурення на швидкість руху ВТЗ вгору, якщо ця швидкість регулюсться алгоритмом квазіінваріантного управління 


\section{Список літератури:}

1. Андрющенко О.А., Булгар В.В., Пассажирский лифт как электромеханическая система. Перспективы и проблемы совершенствования энергетических показателей. Подъемные сооружения. Специальная техника. 2010. №2. С. 23-28.

2. Бойко А.А., Влияние номинальной скорости кабины на производительность пассажирских лифтов. Одесса : Интерпринт, 2013. С. 38-43.

3. Вальков В.М., Вершин В.Е. Автоматизированные системы управления технологическими процессами. Львів : Политехника, 1991. 269 с.

4. Герман-Галкин С.Г. Компьютерное моделирование полупроводниковых систем в Matlab 6.0: Учебное пособие. Санкт-Петербург : КОРОНА Принт, 2001. 320 с.

5. Джина Барни. Эффективность использования энергии в лифтах - предложение по классификации с точки зрения потребления энергии. Лифт. 2010. № 5. С. 25-29.

6. Ефимова О.Н, Кантарбаев У.Р. Энергосберегающие мероприятия в лифтовых установках. Журнал «Поиск», 2015 г.

7. Жолудев И.С. Безредукторный лифтовой привод. Лифтинформ. 2008. №10 (133). С. 75-79

\section{АЛГОРИТМ КВАЗИИНВАРИАНТНОГО УПРАВЛЕНИЯ ЭЛЕКТРОПРИВОДОМ ВЕРТИКАЛЬНОГО ТРАНСПОРТНОГО СРЕДСТВА В РЕЖИМЕ СРЕДНЕСКОРОСТНОГО ПОДЬЁМА}

Предлагается алгоритм квазиинвариантного управления (АКУ), который позволяет уменьшить величину толчкового влияния на скорость прессования вертикального транспортного средства. АКУ не требует использования специальных управляемых роликов, измерителя величины толчка и системы управления роликами.

Ключевые слова: иифровое управление, компьютерное моделирование, алгоритм управления, инвариантные системы, адаптивные системы, динамические системы, конструирование регуляторов, наблюдатели состояния.

\section{ALGORITHM OF QUASI-INVARIANT CONTROL OF ELECTRIC DRIVE OF VERTICAL VEHICLE IN THE MODE OF MEDIUM-SPEED RISE}

An algorithm for quasi-invariant control (QIC) is proposed, which allows reducing the magnitude of the jogging effect on the pressing speed of a vertical vehicle. QIC does not require the use of special controlled rollers, a measure of the magnitude of the push and the control system of the rollers.

Key words: digital control, computer simulation, control algorithm, invariant systems, adaptive systems, dynamic systems, design of regulators, state observers. 